\title{
Former shuttle pilot nominated as NASA head
}

US President Barack Obama announced on 23 May that he is nominating Charles Bolden, a retired Marine general and former spaceshuttle pilot, as NASA administrator.

The announcement came as the space shuttle Atlantis was finishing the last ever mission to the Hubble Space Telescope - fitting, in its way, as Bolden was the pilot on the mission that launched the telescope in 1990. Speaking to the Atlantis astronauts on 20 May, after meeting with Bolden, Obama said: "It's a high priority of mine to restore that sense of wonder that space can provide."

Filling the administrator's post - the position requires confirmation by the Senate - will end months of speculation and delay, during which Bolden's name has been bandied around along with those of other candidates. He has been a favourite of senator Bill Nelson (Democrat, Florida), whom Bolden piloted into space in 1986 on another of his four shuttle flights.

After graduating from the US Naval Academy in 1968 with a degree in electrical science,

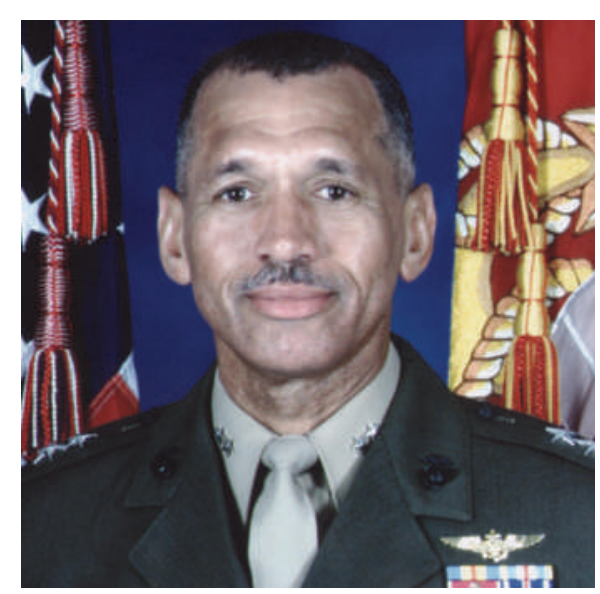

Charles Bolden is in line to take over at NASA.

Bolden began a career as an aviator in the US Marine Corps, becoming an astronaut in 1981. In early 2002, then-administrator Sean O'Keefe picked him to be his deputy, but Bolden wanted to keep his commission while serving at NASA, and there were concerns in the Pentagon and $\sum_{\Sigma}$ Congress over a military officer serving in a civilian position. Bolden's name was withdrawn, and he retired six months later and moved to Houston, Texas, where he became president of a freshwater aquifer development company and served on the boards of oil and aerospace companies.

His views on science are relatively unknown, but Bolden served on a National Academies panel that endorsed a human rather than robotic final servicing of the Hubble Space Telescope. "He was very enthusiastic about the Hubble science," says Louis Lanzerotti, a physicist at the New Jersey Institute of Technology in Newark and the panel's chair. "He seemed to have followed it since he launched the Hubble. He was very alert and inquisitive about the results that were presented to our committee."

Lori Garver, who was a space-policy adviser to the Obama campaign, has been nominated as Bolden's deputy.

Eric Hand 